\title{
Outcome of mobile ear surgery units in Thailand
}

\author{
K Snidvongs, P Vatanasapt*, S Thanaviratananich*, M Pothaporn $\dagger$, P Sannikorn $\dagger$, P Supiyaphun
}

\begin{abstract}
Objectives: To evaluate the outcome of mobile ear surgery, in terms of tympanic membrane perforation closure, absence of otorrhoea and hearing threshold improvement.

Study design: Descriptive study.

Methods: The study enrolled patients with chronic ear disorders requiring surgery who presented to the mobile ear surgery unit at Sakaeo Hospital, Thailand, from 1 to 4 July 2008. The following data were recorded: pre-operative audiogram, post-operative middle-ear and mastoid infection, wound infection, graft condition, any complications, and post-operative audiogram. Patients were followed up at one week, two weeks, four weeks and 24 weeks post-operatively.

Results: For the 31 cases of tympanic membrane perforation, the closure rate was 90.3 per cent. For the 32 patients with otorrhoea, the rate of ear dryness was 87.5 per cent. All 35 patients had impaired hearing initially; the rate of hearing improvement was 74.3 per cent ( 95 per cent confidence intervals $=56.7-87.5$ per cent). Patients' mean hearing improvement was $22.9 \mathrm{~dB}$.

Conclusion: The assessed ear surgery procedures had good results.
\end{abstract}

Key words: Otitis Media; Otologic Surgical Procedures; Myringoplasty; Thailand

\section{Introduction}

In Thailand, access to health care is still not easy in remote areas, particularly when invasive procedures are required. The number of specialists is too low to adequately cover the whole population. For instance, the ratio of otolaryngologists per head of population is 848 per 70000000 . Most otolaryngologists practise in large cities, one-third in Bangkok. Citizens in remote areas usually have a low income and poor hygiene, and often suffer from chronic ear infection. Suppurative otitis media and cholesteatoma can cause major complications and morbidity, such as permanent deafness, facial nerve paralysis, lateral sinus thrombosis, meningitis and brain abscess. The prevalence of intracranial complications equals that of extracranial complications, and more than one complication can occur in any one patient. ${ }^{1}$ Rural transportation is difficult and costly, creating a barrier to appropriate treatment in larger cities. One solution is to share the burden and provide a way for rural people to gain access to health care, via mobile ear surgery units which bring specialists to rural areas.

Mobile ear surgery was first provided in Thailand in 1974, by a small mobile unit organised by Dr Salyaveth Lekagul. This unit comprised two to three otologists with one to two operating microscopes.
In 1981, this programme evolved into the Rural Ear Nose and Throat Foundation. ${ }^{2}$ The present programme provides 'ear camps' consisting of about 20 otologists with up to 12 operating microscopes. Apart from the Foundation, there are also other agencies providing the same kind of mobile ear service, such as the Thai Red Cross Society, IMPACT Thailand Foundation, Rajavithi Hospital, Khon Kaen University and Chulalongkorn University. All serve underprivileged, poor and disabled patients free of charge, with very good cooperation and effective coordination between agencies. For decades, the mobile teams organised by the Rural Ear Nose and Throat Foundation have regularly travelled to the neighbouring countries of Thailand, such as Myanmar, Laos, Cambodia, Vietnam, Bhutan and Southern China, to provide service. Many experienced otologists from Thai training centres, and also from such Western countries as Canada, the US and the UK, regularly come to provide mobile ear surgical services in Thailand every year. ${ }^{3-6}$

From 1 to 4 July 2008, one such mobile ear surgery service was provided at Sakaeo Hospital in Sakaeo province. Sakaeo is located closed to the ThaiCambodia border, $256 \mathrm{~km}$ from Bangkok. The ratio of doctors to population is one per 9983. Per capita income is around US\$1000. Providing ear surgery,

From the Department of Otolaryngology, Faculty of Medicine, Chulalongkorn University, Bangkok, the *Department of Otorhinolaryngology, Khon Kaen University, and the †Department of Otolaryngology, Rajavithi Hospital, Bangkok, Thailand. Accepted for publication: 7 July 2009. First published online 25 November 2009. 
without premedication, to a large number of infected patients within a short space of time is much more complicated than performing carefully scheduled surgery in a well equipped, permanent facility. The objective of this study was to evaluate the outcome of the ear surgery performed by this mobile ear surgery unit, in terms of tympanic membrane perforation closure, absence of otorrhoea and hearing threshold improvement. In addition, we aimed to correlate the perforation closure rate with the type of ear discharge and the size of the perforation.

\section{Materials and methods}

The study was approved by the Chulalongkorn University Faculty of Medicine institutional review board and ethics committee. Consent was obtained from all participants.

The study was performed prospectively. Subjects comprised patients with chronic ear disorders requiring middle-ear or mastoid surgery who presented to the mobile ear surgery unit at Sakaeo Hospital, Sakaeo province, Thailand, from 1 to 4 July 2008. The mobile ear surgery unit was organised by the Rural Ear Nose and Throat Foundation, in cooperation with Rajavithi Hospital, IMPACT Thailand Foundation, the Thai Red Cross Society and the Ministry of Public Health.

The unit team consisted of eight experienced ear surgeons, an additional 14 otologists, two audiologists, five nurses and one manager. Surgical supplies comprised eight operating microscopes, eight hydraulic chairs, and 60 sets of surgical instruments, drapes, drills and stapes prostheses. Surgical instruments and drapes were sterilised using steam. All supplies were brought from Bangkok. The target population in Sakaeo was informed of the coming of the mobile ear surgery unit using posters and radio broadcasts. With coordination from the Ministry of Public Health, district hospitals referred appropriate cases to the mobile team. There were eight surgical beds (functioning as operating tables) in two operating theatres; the surgical beds were approximately two metres apart. One hundred bodytype hearing aids (Guangdong Medical Equipment Industrial, Guangdong, China), plus all necessary medication, were also brought from Bangkok.

The indications for surgery were persistent tympanic membrane perforation lasting longer than three months, cholesteatoma, otosclerosis, and ossicular fixation and disruption. Exclusion criteria included acute otitis externa, ear canal stenosis to a diameter of less than $4 \mathrm{~mm}$, atelectasis of the tympanic membrane without cholesteatoma, and tuberculous otitis media. Tympanoplasty procedures used an overlay technique via an end-aural approach. Mastoidectomy usually involved drilling down of the posterior canal wall, with middle-ear preservation and reconstruction if possible. A small fenestra stapedotomy with $0.6 \mathrm{~mm}$ piston prosthesis was used for stapes surgery. An autologous incus was used for ossicular reconstruction. If the incus was not available, other materials were used, such as cartilage, partial ossicular replacement prosthesis or total ossicular replacement prosthesis. Patients received post-operative antibiotics for two weeks, either amoxicillin or amoxicillin with clavulanate. Patients were followed up one week, two weeks, four weeks and 24 weeks post-operatively. Every visit, the next follow-up date was reminded to all patients.

The following data were recorded: demographic data; pre-operative audiogram; operative findings (including the state of the external ear canal, tympanic membrane perforation size and ear discharge type); type of surgery; type of packing; post-operative antibiotics; post-operative findings at follow up (i.e. on the first, second, fourth and 24th post-operative week; relevant findings included middle-ear and mastoid infection, wound infection, graft condition and any other complications); and 24th week post-operative audiogram. Surgical success was assessed in terms of tympanic membrane perforation closure, absence of otorrhoea and hearing threshold improvement. Hearing improvement was defined as a post-operative air conduction threshold reduction of at least $10 \mathrm{~dB}$, compared with the pre-operative threshold. Follow-up assessment was carried out by the first author and trainees from Chulalongkorn University.

\section{Results and analysis}

Thirty-five patients underwent ear surgery at the mobile unit, out of 400 out-patients seen. Fifteen (42.9 per cent) patients were male and 20 (57.1 per cent) female. Patients' ages ranged from 10 to 83 years, with a mean of 44.4 years (standard deviation 17.9). Presenting symptoms included otorrhoea in 27 cases (77.1 per cent), hearing loss in 25 cases (71.4 per cent), otorrhoea with hearing loss in 17 cases (48.6 per cent) and an itchy ear in one case (2.9 per cent). The mean duration of symptoms was 16.7 years (95 per cent confidence interval (CI) 10.323.2). Three patients had co-morbidities, including asthma (one case), hypertension (two), dyslipidaemia (one) and diabetes mellitus (one).

Twenty-nine (82.9 per cent) patients underwent overlay tympanoplasty. One of these 29 also underwent simultaneous ossiculoplasty. Three (8.6 per cent) patients had cholesteatoma and underwent canal wall down mastoidectomy; two of these three also underwent simultaneous tympanoplasty. Three (8.6 per cent) patients were diagnosed with otosclerosis and underwent stapedectomy. Surgery was performed on the left side in 19 (54.3 per cent) cases, and on the right side in the remainder. Operative findings are displayed in Table I.

External ear packing comprised rayon with cotton in 31 (88.6 per cent) cases, Gelfoam (Pfizer Manufacturing, Puurs, Antwep, Belgium) in 33 (94.3 per cent) cases and Sofratulle (Hoechst Marion Roussel, Bridgewater, New Jersey, USA) in five (14.3 per cent) cases.

Post-operative antibiotics were given in all cases; 33 (94.3 per cent) patients received amoxicillin and two (5.7 per cent) amoxicillin with clavulanate.

Six of 31 (19.4 per cent) tympanic membrane perforations were small (i.e. 11-50 per cent perforation), 12 (38.7 per cent) were large (i.e. 51-90 per cent) and 
TABLE I

INTRA-OPERATIVE FINDINGS

\begin{tabular}{lc}
\hline Finding & $\mathrm{Pts}^{*}(n(\%))$ \\
\hline TM perforation & $31(88.6)$ \\
Cholesteatoma & $3(8.6)$ \\
Aural polyp & $2(5.7)$ \\
Otosclerosis & $3(8.6)$ \\
\hline
\end{tabular}

*Total $n=35$. Pts $=$ patients; $\mathrm{TM}=$ tympanic membrane

13 (41.9 per cent) were near-total or total (i.e. $91-100$ per cent). Four patients had intact ear drums (three cases of otosclerosis and one of cholesteatoma). Fifteen (42.9 per cent) ears were dry. Seventeen (48.5 per cent) patients had purulent discharge, although 13 of these 17 had only minimal pus. Two (5.7 per cent) patients had mucoid discharge and one (2.9 per cent) mucopurulent discharge.

Patients' mean pre- and post-operative hearing thresholds are displayed in Table II. Table III shows patients' follow-up results, in terms of otorrhoea, wound infection and tympanic membrane healing. The patients' mean hearing threshold was reduced from $60.1 \mathrm{~dB}$ pre-operatively (95 per cent CI 52.6-67.5) to $37.0 \mathrm{~dB}$ post-operatively (95 per

TABLE II

MEAN PRE- AND POST-OPERATIVE HEARING THRESHOLDS

\begin{tabular}{lcc}
\hline Parameter & \multicolumn{2}{c}{ Threshold (dB (95\% CI)) } \\
\cline { 2 - 3 } & \multicolumn{1}{c}{ Pre-op } & 24-wk post-op \\
\hline Left ears & & \\
AC & $53.9(46.0-61.8)$ & $36.7(30.6-42.7)$ \\
BC & $22.2(17.0-27.4)$ & $25.0(20.5-29.5)$ \\
ABG & $31.7(26.3-37.2)$ & $11.5(7.2-15.8)$ \\
Right ears & & \\
AC & $52.7(44.2-61.2)$ & $38.8(31.2-46.5)$ \\
BC & $23.3(17.5-29.2)$ & $26.2(20.4-32.0)$ \\
ABG & $29.2(22.2-36.2)$ & $12.3(7.2-17.5)$ \\
\hline
\end{tabular}

$\mathrm{CI}=$ confidence $\quad$ interval; $\quad$ pre-op $=$ pre-operative; $24-\mathrm{wk}$ post-op $=24$ week post-operative; $\mathrm{AC}=$ air conduction $\mathrm{BC}=$ bone conduction; $\mathrm{ABG}=$ air - bone gap cent CI 30.6-43.4) $(p<0.0001)$. Patients' postoperative bone conduction thresholds were not significantly different from pre-operative levels. Hearing was improved in 26 of the 35 ear surgery patients (74.3 per cent; 95 per cent CI 56.7-87.5 per cent). Of the 32 patients undergoing tympanoplasty and/or mastoidectomy, a dry ear was seen in 96.9 per cent at one week's follow up, 75.0 per cent at two weeks, 81.3 per cent at four weeks and 87.5 per cent at 24 weeks. Of the 35 ear surgery cases, wound infection was observed in 5.7 per cent at one week's follow up, 14.3 per cent at two weeks, and 0 per cent at four and 24 weeks. Of the 31 cases of tympanic membrane perforation, the closure rate was 83.9 and 90.3 per cent at the fourth and 24th follow-up week, respectively. (In most cases, tympanic membrane healing could not be assessed at one and two weeks' follow up because the ears were packed.)

All three stapedectomy cases had improved postoperative hearing; the air-bone gap was reduced from 56 to $6 \mathrm{~dB}, 58$ to $20 \mathrm{~dB}$ and 36 to $3 \mathrm{~dB}$, variously. All had post-operative vertigo for one day and recovered with conservative treatment. No further complications were noted at one, two, four and 24 weeks' follow up.

We could not analyse the association between tympanic membrane healing and otorrhoea type because the number in each group was too small. Interestingly, all cases with frank purulent otorrhoea had healed by the 24th post-operative week (Table IV).

Regarding ear drum perforation size, we observed that all small perforations had healed by the 24th post-operative week (Table V).

\section{Discussion}

Several previous studies have assessed the outcomes of mobile ear surgery units. A mobile unit in Greenland had a tympanoplasty success rate of 76 per cent, with a mean pure tone average improvement of $12 \mathrm{~dB}^{7}$ An ear camp in Namibia had a tympanic membrane closure rate of 83 per cent, with an average air conduction threshold improvement of

TABLE III

PATIENTS' POST-OPERATIVE RESULTS

\begin{tabular}{|c|c|c|c|c|}
\hline \multirow[t]{2}{*}{ Outcome } & \multicolumn{4}{|c|}{ Post-operative week ( $n(\%))$} \\
\hline & 1 & 2 & 4 & 24 \\
\hline \multicolumn{5}{|l|}{ Otorrhoea* } \\
\hline Dry & $31(96.9)$ & $24(75.0)$ & $26(81.3)$ & $28(87.5)$ \\
\hline Minimal pus & $1(3.1)$ & $3(9.4)$ & $1(3.1)$ & $2(6.3)$ \\
\hline Frank pus & 0 & 0 & $2(6.3)$ & $1(3.1)$ \\
\hline Mucoid & 0 & $2(6.3)$ & $2(6.3)$ & $1(3.1)$ \\
\hline Mucopurulent & 0 & $2(6.3)$ & $1(3.1)$ & 0 \\
\hline Pulsatile & 0 & $1(3.1)$ & 0 & 0 \\
\hline Wound infection $^{\dagger}$ & $2(5.7)$ & $5(14.3)$ & 0 & 0 \\
\hline \multicolumn{5}{|l|}{ TM healing } \\
\hline Healed & $1(3.2)$ & $27(87.1)$ & $26(83.9)$ & $28(90.3)$ \\
\hline Unhealed & 0 & 0 & $5(16.1)$ & $3(9.7)$ \\
\hline Obscured by packing & $30(96.8)$ & $4(12.9)$ & 0 & 0 \\
\hline
\end{tabular}

${ }^{*} n=32$; excluding stapedectomy cases. ${ }^{\dagger} n=35 ;{ }^{\star} n=31$; excluding stapedectomy and mastoidectomy without myringoplasty.

$\mathrm{TM}=$ tympanic membrane 
TABLE IV

TYMPANOPLASTY RESULTS BY EAR DISCHARGE TYPE

\begin{tabular}{lccr}
\hline Discharge & \multicolumn{2}{c}{ TM at 24 wks $(n)$} & Total $(n)$ \\
\cline { 2 - 3 } & Healed & Unhealed & \\
\hline Dry & 11 & 1 & 12 \\
Minimal pus & 12 & 1 & 13 \\
Frank pus & 3 & 0 & 3 \\
Mucoid & 1 & 1 & 2 \\
Mucopurulent & 1 & 0 & 1 \\
Total & 28 & 3 & 31 \\
\hline
\end{tabular}

$\mathrm{TM}=$ tympanic membrane; wks $=$ weeks

$15 \mathrm{~dB} .^{8}$ A mobile ear surgery unit in Mexico had a tympanoplasty success rate of 74 per cent. ${ }^{9}$ These results are less successful than those of fully equipped hospitals, which have reported tympanoplasty success rates of approximately 90 per cent (i.e. intact tympanic membrane with at least $15 \mathrm{~dB}$ hearing improvement). ${ }^{10}$ However, mobile ear surgery units have reported results for chronic, noncholesteatomatous, granulating otitis with discharge similar to those for tympanoplasty performed in established hospitals (even training centres), where the re-operation rate is approximately 16 per cent. ${ }^{11}$

Our closure rate of 90.3 per cent was close to that reported for well equipped, permanent centres. This could be due to many factors.

Firstly, we allowed only experienced otologists to perform the surgery. This was done in order to reduce confounding factors and thereby facilitate outcomes analysis for a mobile unit performing 35 surgical procedures per day. (However, in Bhat and colleagues' study, the success rates of consultants and trainees for myringoplasty were found to be similar. $)^{12}$

Secondly, our level of hygiene in the operation theatre and in-patient ward, and for medical instruments and equipment, was of international standard. All sets of surgical instruments and drapes were brought from Bangkok and steam-sterilised to ensure the absence of contamination. In addition, Sakaeo Hospital is well operated, and accredited by the Institute of Hospital Quality Improvement and Accreditation.

The patients' hearing improvement rate $(74.3$ per cent) was not as high as their perforation closure rate ( 90.3 per cent), and their mean hearing threshold improvement was $22.9 \mathrm{~dB}$. These figures could have

TABLE V

TYMPANOPLASTY RESULTS BY TM PERFORATION SIZE

\begin{tabular}{lccc}
\hline Perforation size & \multicolumn{2}{c}{ TM at 24 wks $(n)$} & \multirow{2}{*}{ Total $(n)$} \\
\cline { 2 - 3 } & Healed & Unhealed & \\
\hline Small* $^{\dagger}$ & 6 & 0 & 6 \\
Large $^{\dagger}$ & 11 & 1 & 12 \\
Near-total \& total $^{*}$ & 11 & 2 & 13 \\
Total patients & 28 & 3 & 31 \\
\hline
\end{tabular}

*11-50 per cent; ${ }^{\dagger} 51-90$ per cent; ${ }^{\ddagger} 91-100$ per cent; TM = tympanic membrane; wks $=$ weeks been influenced by undetected ossicular chain disruption; the surgeons did not explore the continuity of the ossicles in all cases. Patients whose tympanic membrane perforations healed without any hearing improvement may require ossiculoplasty or hearing aids in the future.

Surgery performed in the mobile unit differed from that undertaken in a permanent hospital in three main respects: four surgical beds were sited within the one operating theatre; no premedication was given; and a large number of procedures were conducted per day. These limitations could have resulted in contamination, wound infection and surgical failure. To the best of our knowledge, there are no English language studies assessing the appropriate, safe distance between two surgical fields, as most hospitals worldwide have only one operating table per operating theatre. The rate of wound infection in our study was as high as 14.3 per cent, although all cases subsequently resolved. We believe that the above-mentioned limitations did not significantly affect our surgical results, as the mobile unit was clean, effectively managed and staffed by an experienced team.

- This study evaluated the outcome of a Thai mobile ear surgery unit regarding tympanic membrane (TM) perforation closure, absence of otorrhoea and hearing improvement

- Ear surgery in the mobile unit was complicated by the following: four surgical beds in one operating theatre; no premedication; and large numbers of infected patients treated per day

- Patients' rates of TM closure (90.3 per cent), was close to those for well equipped, permanent centres

- Provided sterility and hygiene standards are observed, mobile ear surgery units are useful ventures for remote populations with limited access to health services

Another limitation of this study was that the follow-up period, at 24 weeks, was short compared with that reported by other studies (e.g. more than a year). Our patients' success rates may possibly have reduced after six months, because we could not correct all causative factors in our patients' chronic ear diseases. Further studies of the long term outcomes of Thai mobile ear surgery units may be required.

\section{Conclusion}

Mobile ear surgery units have a long history in Thailand, and have served the Thai population in remote areas for more than 30 years. Surgery is undertaken within rural hospitals, because sterility and hygiene are key factors for success. The Sakaeo Hospital ear camp had good ear surgery outcomes, in terms of tympanoplasty closure, absence of otorrhoea and 
hearing improvement. The mobile ear surgery unit is a useful venture for remote populations with limited access to health services.

\section{Acknowledgements}

The authors wish to thank all the consultants who worked in the mobile ear surgery unit, including Drs J Chokdumrongsuk, W Jindaratana, K Komin, P Ngaotepplutharam, D Nunpradech, V Vaedao, $\mathrm{P}$ Apipan, V Chantharochavong, $\mathrm{T}$ Thanjarakul, C Banditkul, D Yaowapolkul and P Buranakarnjaroen, and all the participating residents from the Rajvithi Hospital and King Chulalongkorn Memorial Hospital, for sharing their technical expertise in middle-ear and mastoid surgery and chronic ear disease management. We acknowledge the contribution of J Sruangpo and T Engkawisan in testing the hearing thresholds of all patients. We thank the Thai Red Cross nurses, including A Watcharotayangkura, W Dechatiwong Na Ayudhaya, U Boonplian, S Supudommungmee and A Sripatthangkura, for their excellent nursing care, and also the staff of Sakaeo Hospital for their kind contribution and effective cooperation. We acknowledge and express our appreciation for grants received from the Ratchadapiseksompoch Research Fund, Chulalongkorn University, for the development of new faculty staff. Lastly, our thanks go particularly to Drs S Lekagul and $\mathrm{S}$ Antarasena for their technical advice and continual inspiration to the junior otolaryngologists of Thailand.

\section{References}

1 Mostafa BE, El Fiky LM, El Sharnouby MM. Complications of suppurative otitis media: still a problem in the 21st century. ORL J Otorhinolaryngol Relat Spec 2009;71: $87-92$

2 Antarasena S. The history of the Rural Ear Nose and Throat Foundation. Thai Journal of OtolaryngologyHead and Neck Surgery 1988;3:3-8
3 Alberti PW. Rural ear camps in Thailand. J Otolaryngol 1990; 19:413-15

4 Jahn AF. Ear surgery in rural Thailand: a trip diary. J Otolaryngol 1990;19:399-412

5 Wilson LJ, Wilson J. Personal impressions of a visit to the Thai Rural Ear Foundation. J Otolaryngol 1990;19:416-17

6 Wilson J. Disability in Thailand. J Otolaryngol 1990;19: 396-8

7 Homoe P, Siim C, Bretlau P. Outcome of mobile ear surgery for chronic otitis media in remote areas. Otolaryngol Head Neck Surg 2008;139:55-61

8 Lehnerdt G, van Delden A, Lautermann J. Management of an "Ear Camp" for children in Namibia. Int J Pediatr Otorhinolaryngol 2005;69:663-8

9 Barrs DM, Muller SP, Worrndell DB, Weidmann EW. Results of a humanitarian otologic and audiologic project performed outside of the United States: lessons learned from the "Oye, Amigos!" project. Otolaryngol Head Neck Surg 2000;123:722-7

10 Podoshin L, Fradis M, Malatskey S, Ben-David J. Tympanoplasty in adults: a five-year survey. Ear Nose Throat $J$ 1996;75:149-52, 55-6

11 Lau T, Tos M. Long-term results of surgery for chronic granulating otitis. Am J Otolaryngol 1986;7:341-5

12 Bhat NA, De R. Retrospective analysis of surgical outcome, symptom changes, and hearing improvement following myringoplasty. J Otolaryngol 2000;29:229-32

Address for correspondence:

Dr Kornkiat Snidvongs,

Department of Otolaryngology,

Faculty of Medicine,

Chulalongkorn University,

Bangkok 10330, Thailand.

Fax: (662) 2527787

E-mail: drkornkiat@yahoo.com

Dr K Snidvongs takes responsibility for the integrity of the content of the paper.

Competing interests: On the board of directors of the Rural Ear Nose and Throat Foundation, Dr P Supiyaphun serves as vice president and Dr K Snidvongs as secretary general; Dr P Sannikorn is a committee board member. None of the authors receive fees, salary, gifts or indirect financial support from The Rural Ear Nose and Throat Foundation. 